\title{
Measurement of Spindle Thermal Growth on a Machine Intended for Micro / Meso Scale Milling
}

\author{
J.B. Saedon ${ }^{1,2, a}$, S.L. Soo ${ }^{1, b}$ and D.K. Aspinwall ${ }^{1, c}$ \\ ${ }^{1}$ Machining Research Group, School of Mechanical Engineering, University Of Birmingham, \\ Edgbaston, Birmingham, United Kingdom. \\ ${ }^{2}$ Faculty of Mechanical Engineering, Universiti Teknologi MARA, Malaysia.

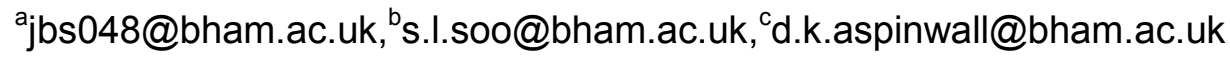

Keywords: Micro-milling, cutting, spindle thermal growth.

\begin{abstract}
Micro milling is gaining ground as the preferred process for the manufacture of micro/meso-scale components in conventional workpiece materials, in particular for miniature moulds and tooling inserts $(\sim 60 \mathrm{HRC})$, for the plastics injection moulding industry. Following a brief literature review on microscale milling and associated machine tool/tooling developments, experimental results are presented in relation to spindle thermal growth for a compensated/cooled spindle operating at up to $60,000 \mathrm{rpm}$, designed to accommodate the machining of mesoscale/micro-scale components. The work involved investigation of spindle warm up and cool down rates for speeds ranging from 30,000 - 60,000 rpm and subsequently the evaluation of spindle growth using both non-contact and contact measuring systems. Growth levels of up to $16 \mu \mathrm{m}$ were detected despite active spindle cooling and the incorporation of a standard compensation algorithm within the control system. Modification to spindle acceleration and deceleration rates reduced error levels by up to $50 \%$.
\end{abstract}

\section{Introduction}

Demand and production for micro or miniature parts is increasing significantly year on year with volume manufacture reliant on advances in replication techniques such as micro-injection moulding, hot embossing etc. In their turn, these processes depend on the production of appropriate tooling to meet a specific product need. Traditional micro fabrication techniques rely on lithography/etching or energy beam methods which are ideally suited to planar materials processing involving silicon based materials. For more complex 3D components with high aspect ratio features encompassing mainstream ferrous, non-ferrous and non-metallic materials other than silicon, microscale high speed milling offers a more direct and effective processing route and is ideally suited to the manufacture of tools and dies. Typically, microscale milling involves the use of high speed machine spindles with rotational speeds up to $\sim 160,000 \mathrm{rpm}$ but more realistically $50,000-$ $60,000 \mathrm{rpm}$ and tooling in the range $60 \mu \mathrm{m}$ to $1 \mathrm{~mm}$ in diameter. Despite the terminology, some commercial machines for cutting at the microscale level are comparable in size (machine footprint) to general purpose high speed machining centres although a number of table top systems are also available in the marketplace [1].

Up until the 1980's, the machining of components for the watch industry represented the majority of application work in microscale mechanical machining, however this essentially involved $2-2.5 \mathrm{D}$ components/features. Much of the current academic and industrial interest in microscale machining stems from developments over the past $10-15$ years. Key review papers concerned with the mechanics of machining at the microscale level which identify the current state of the art together with future areas of research are those by Liu et al. [2], Dornfeld et al. [3], Chae et al. [4], Robinson et al. [5] and Gowri et al. [6]. The papers focus on a number of process characteristics which affect cutting at the microscale level and which are raised by other researchers, namely tool edge radius effects in relation to the undeformed chip thickness, workpiece grain size/microstructural effects and the mechanism of cutting (ploughing/rubbing vs. shearing) with consequent effects on built up edge (BUE) formation, cutting forces, tool wear, workpiece 
surface roughness and burr formation. Much of the information detailed in the review papers relates to micro-turning rather than micro-milling and there are notable knowledge gaps with respect to thermal measurement, workpiece integrity effects and modelling. Recent publications encompassing micro-milling include Liu et al. [7], Li et al. [8], Aramcharoen and Mativenga [9] and Aramcharoen et al. [10]. The two papers by Liu et al. [2, 7] provide useful insight in respect of micro-fluidic device manufacture, particular micro-channel side wall roughness. The remaining three concentrate on the micro-milling of hardened steels and highlight challenges such as unpredictable tool life/premature tool failure and differences in process mechanisms compared to macroscale machining. Data is also reported on the performance of hard coatings, which highlight TiN as preferable when micro-milling AISI H13 (45 HRC) in contrast to harder and more complex TiAlN, CrTiAlN products favoured when using larger end mills in macroscale cutting operations. Anticipated reasons for this relate to the level of coating adhesion and the fact that oxidation performance is unlikely to be a significant factor.

As outlined earlier, an essential machine tool feature for micro-milling involves a high speed spindle in order to achieve even moderate peripheral cutting speeds when employing end mills of the order of $500 \mu \mathrm{m}$ to $1 \mathrm{~mm}$ diameter. Commercial micro-milling machines include the KERN Micro, Evo \& Pyramid Nano, KUGLER MicroMaster and FANUC Robonano $\alpha-0 i B$. While some of these are able to operate at up to $160,000 \mathrm{rpm}$, the majority are sold with spindles capable of up to $50,000 \mathrm{rpm}$, in part due to tool performance restrictions. For workpiece materials such as stainless steel or more exotic aerospace alloys, the day to day operating spindle speed may be substantially lower e.g. $<10,000 \mathrm{rpm}$ or even $5,000 \mathrm{rpm}$. Consequently a more practical/workable solution is a machine capable of using alternative/multiple spindles with one able to operate at say $500-50,000 \mathrm{rpm}$ with another designed for use at 60,000 to $90,000 \mathrm{rpm}$ or 110,000 to $160,000 \mathrm{rpm}$ [11]. Similarly, more general purpose machines such as the Matsuura LX-1/LX-0 linear motor systems which utilises a 60,000rpm spindle as standard but can be specified with an 80,000rpm unit, are able to accommodate micromachining with $\sim 200 \mu \mathrm{m}$ cutters but also much larger macroscale end mills and abrasive tooling products with a work table area of up to $700 \times 500 \mathrm{~mm}$. Machine positional accuracy/precision is also critical. Here, quoted axis positioning is at the submicron level $(\sim \pm 0.5 \mu \mathrm{m}$ or in some cases better) but such values can be misleading and is generally higher than that achieved on the workpiece with an average value for this being within $2 \mu \mathrm{m}$.

Machine price is dependant on specification and ancillary requirements such as workpiece transfer hardware, number of controllable axes, workpiece probing, number of spindles supplied etc. however systems are available typically within the range of $£ 150,000-£ 400,000$. A cheaper option is the purchase of a retrofit high speed spindle with associated cooling and control equipment. Systems rated at $60,000,90,000$ or $120,000 \mathrm{rpm}$ can be purchased off the shelf for $£ 6,000-£ 15,000$ depending on tool mounting arrangements (collet, shrink fit, etc), however such systems are at best ad-hoc and can present problems in terms of location/fitting requirements, $\mathrm{z}$ axis machine restrictions, axis float and automatic tool changing etc. Spindle power with motor driven systems is not a critical issue for microscale machining, however the move from microscale to mesoscale can present problems with air driven units. In terms of cutting tools, a wide range of multi-fluted solid carbide micro-tooling (milling, drilling etc.) is readily available from a host of mainstream suppliers, in some cases down to $\sim 60 \mu \mathrm{m}$ diameter and 'off the shelf', although 100 $\mu \mathrm{m}$ diameter is more representative. The tools typically have a 3,4,6 mm diameter shank for mounting. Milling tools $\sim 50 \mu \mathrm{m}$ diameter can be obtained as bespoke products. Cost of such tooling is not exorbitant and in many cases compares favourably with macroscale products.

Thermal distortion effects due to motor and bearing arrangements can be significant and machines generally employ cooling systems and spindle growth compensation algorithms in order to minimise z-axis errors. Difficulties with process monitoring when using force dynamometry due to the fact that cutting force signals when micromachining can be difficult to distinguish from the machine tool background noise, put greater emphasis on machine stability and accuracy than with macroscale systems. Spindle growth of only a few microns $(<5 \mu \mathrm{m})$ has relatively little consequence when macroscale machining, not least because depths of cut are typically $>0.1 \mathrm{~mm}$ 
and tool wear is a more dominant feature. In contrast, when machining at the microscale level with axial depths of cut of $\sim 10$ to $20 \mu \mathrm{m}$, a $5 \mu \mathrm{m}$ error due to spindle growth is highly significant with regard to both feature accuracy and corresponding tool life. Relevant papers on thermal error measurement and compensation include those by Ramesh et al. [12], Pahk and Lee [13] and Weck et al. [14]. The following case study/experimental work was undertaken to determine spindle z-axis growth using a commercial high speed micromachining centre operating over a range of speeds and with varying duty cycles.

\section{Experimental work}

The research was undertaken on a linear motor driven 3-axis vertical CNC machining centre employing a motorised 60,000 rpm integrally cooled (by oil) and compensated spindle. The specification of the machine tool accorded with that of a micro-milling unit able to accommodate cutters down to $100 \mu \mathrm{m}$ using shrink fit tooling adapters while also enabling larger tools (up to 12 $\mathrm{mm}$ diameter) and cutting operations to be undertaken. Visual inspection of the cutting process was facilitated using a miniature camera located within the machine tool enclosure connected to an external flat screen monitor. On-machine measuring equipment included a Renishaw NC-3 noncontact laser tool setting unit, a Renishaw OMP 40 contact probe system for workpiece inspection and a Mitutoyo dial gauge indicator (DTI) with $1 \mu \mathrm{m}$ resolution. Contact measurements utilised a blunt/'dummy tool' (reverse end of milling tool). To avoid problems with BUE and tool wear during machining tests, the workpiece material employed was graphite $(150 \mathrm{~mm} \times 110 \mathrm{~mm} \times 50$ $\mathrm{mm}$ block). Cutting tools were twin flute, $6 \mathrm{~mm}$ diameter PCD end mills. The rationale for using relatively large tools (instead of sub-millimetre cutters) was principally to facilitate measurement.

The work was divided into two phases (Phase 1 and 2). Phase 1 initially investigated variation in the temperature of the laboratory in which the machine tool was located. This encompasses some $1100 \mathrm{~m}^{3}$ of space with high speed machining centres, creep feed grinding systems, CNC lathes etc. and due to the scale involved, environmental control is basic as with standard industrial facilities. Following on from this, the spindle temperature during machine warm-up and cool-down cycles (from cold) at rotational speeds of $30,000,40,000,50,000$ and $60,000 \mathrm{rpm}$ was evaluated. Temperature values were recorded at specific time intervals from the spindles' own sensor output onto the control panel, with testing spread over a period of several days. Additionally, measurements were also taken with the machine baseline temperature varying between $15^{\circ} \mathrm{C}$ and $18^{\circ} \mathrm{C}$. Measurements of spindle displacement/change in tool z-axis position during a spindle cooling cycle followed a standard machine warm up sequence undertaken according to manufacturers' guidelines. This therefore simulated normal operating practice such that any displacement was due to supplementary cooling during spindle down time and any thermal lag. In practice, displacement will depend on the spindle start-stop regime and rotational speed and with increasing periods of down time, greater z-axis error will occur. Fig. 1 gives a schematic of the machine spindle arrangement and shows the ceramic bearing positions adjacent to where temperatures were monitored. Temperature output on the machine control panel for Phase 1 work reflected variation associated with bearing 2 located near to the spindle nose.

Phase 2 work involved evaluation of spindle growth when operating at 60,000 rpm with measurements taken using the 'dummy tool' and following a machining operation on the graphite workpiece. With the dummy tool, a programme was written to incorporate spindle operation in 5 minute intervals with a 3 second measuring period during which the spindle was stopped. The dummy tool approached and contacted the DTI using a step-down federate sequence, see Fig. 2 for the general arrangement. A similar methodology was adopted for non contact measurement with the NC-3 laser tool setting unit. Investigation of spindle growth during actual machining involved dry cutting of test slots using a federate of $50 \mathrm{~mm} / \mathrm{min}$ and a depth of cut of $50 \mu \mathrm{m}$ with a bearing base temperature of $18^{\circ} \mathrm{C}$. The actual slot depth on the workpiece was measured using the OMP 40 (Fig. 3 ) contact probe mounted in the spindle with the average of three measurements at each assessment position on the slot (correlated with cutting time) recorded graphically as a calibration curve. 


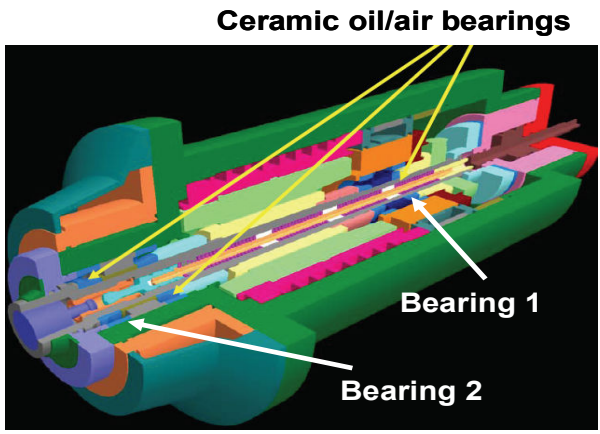

Fig. 1 Spindle / bearing details

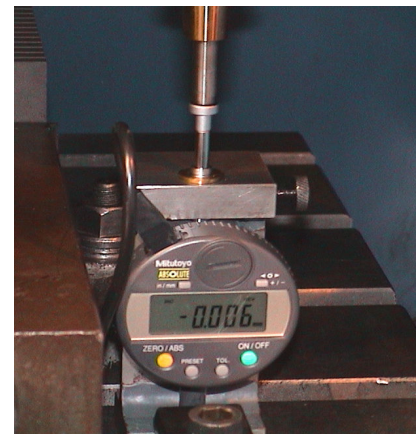

Fig. 2 Dummy tool measurement using DTI

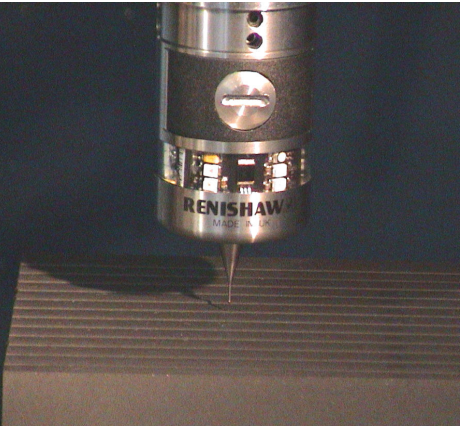

Fig 3 Slot depth measurement in graphite using OMP 40

\section{Results and discussion}

Although not shown graphically, variation in lab temperature from 0900 to 2000 changed by approximately $3{ }^{\circ} \mathrm{C}$ to $4^{\circ} \mathrm{C}$ on a typical day however seasonal variation was not taken into account. The variation in tool length due to this change (measured without spindle rotation) was approximately $4 \mu \mathrm{m}$ to $5 \mu \mathrm{m}$ as a consequence of machine tool flexure. Fig. 4 gives spindle warm up and cool down time-temperature response curves for Phase 1 work. Cessation of spindle rotation occurred once the temperature for a given rotational speed had been judged to plateau. At 30,000 $\mathrm{rpm}$, this occurred after $\sim 4$ minutes while at 60,000 rpm it was 12 minutes and produced a rise in temperature of $35^{\circ} \mathrm{C}$ (from $17^{\circ} \mathrm{C}$ to $52^{\circ} \mathrm{C}$ ) at the measurement location. Cool down time took 2 to 3 times longer than warm up. Fig. 5 details data for a fixed rotational speed of 30,000 rpm and shows different baseline temperatures (ambient room temperature) experienced in the laboratory. Spindle rotation was actuated once the sensor temperature (at bearing 2) had reached the pre-determined test value. Here the rise in temperature for the different response curves is essentially the same at $6 / 7^{\circ} \mathrm{C}$. As expected, the plateau region coincided for the majority of baseline (initial) temperatures. It should be borne in mind that measurements were undertaken whilst the active cooling system was operational and that without this, the temperature rise from 'cold' would have been substantially higher. In any event, the spindle is subject to automatic shut-down if bearings 1 and 2 reach a defined temperature above the baseline value, however in the current tests, this was not reached.

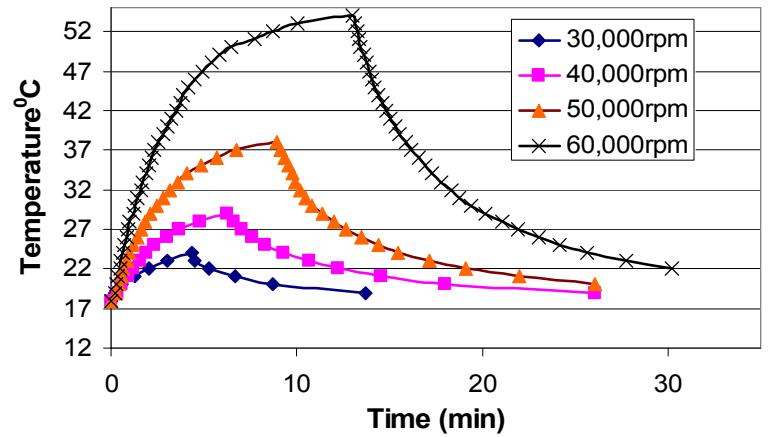

Fig. 4 Warm up and cool down responses at various speeds at a base temperature of $17^{\circ} \mathrm{C}$.

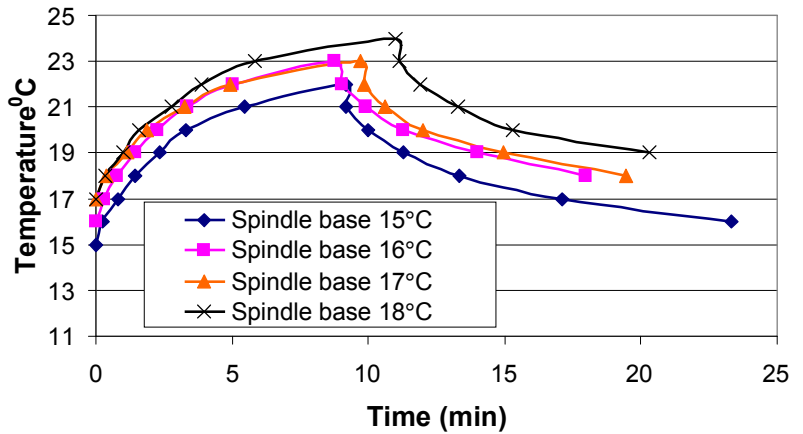

Fig. 5 Warm up and cool down at different base temperatures when rotating at $30,000 \mathrm{rpm}$.

Fig. 6 (initial Phase 2 work) details multiple consecutive warming up and cooling cycles when operating at $60,000 \mathrm{rpm}$ essentially to highlight the repeatability of the rate of spindle temperature rise and also the effect of cooling truncation. Here, the period during which the spindle is not rotating and therefore is cooling (10 minutes) is arguably at the limit of operation before a further warm up cycle is necessary. This is evident in Fig. 7 which shows the cooling phase and associated z-axis variation for Cycle 4 . With the spindle stopped, the sensor adjacent to the spindle nose bearing 2 shows a fall from approximately $\sim 56^{\circ} \mathrm{C}$ to $\sim 31^{\circ} \mathrm{C}$ over the 10 minute cooling period. In 
contrast, the z-axis experiences rapid 'growth' of $\sim 16 \mu \mathrm{m}$ during the first $\sim 3$ minutes before returning as expected to 'zero' after a further 7 minutes. The apparent lag in z-axis growth could be due in part to spindle thermal transfer (conductive) to the head casing and x-axis bridge of the machine (which are not subject to active cooling).

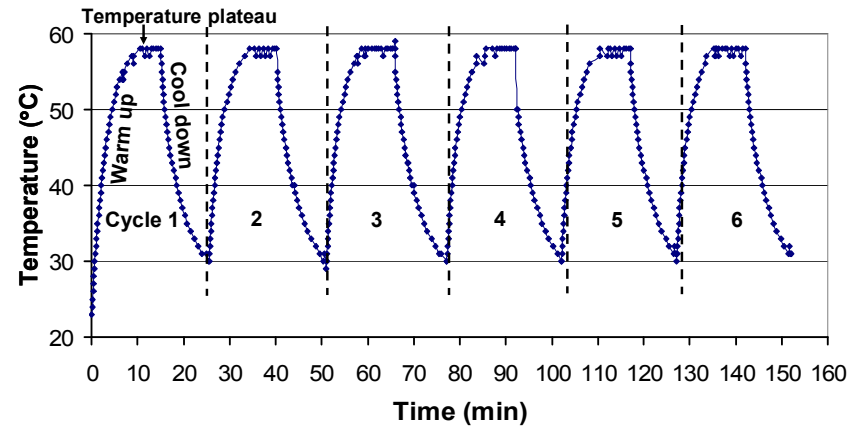

Fig. 6 Spindle warm up and cool down over a 6 cycle period when operating at $60,000 \mathrm{rpm}$

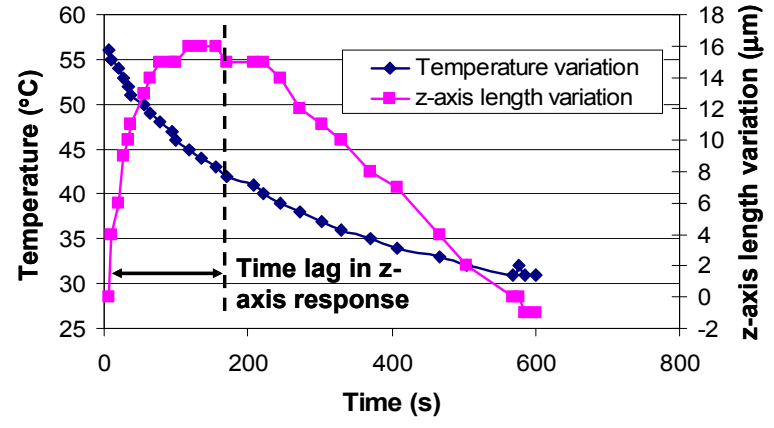

Fig. 7 Z-axis length variation during cooling phase with spindle stationary

Fig. 8 shows the z-axis length variation during spindle operation at 60,000 rpm following a standard warm-up cycle. Here, the spindle growth of approximately $15 \mu \mathrm{m}$ measured with both the DTI and NC3 systems was only attained after a much longer period of operation (25 - 35 minutes) and the apparent disparity in results in relation to those detailed in Fig. 7 has not yet been established. The only significant difference being that the results from Fig. 7 relate to measurements with the spindle stationary for a prolonged period (10 minutes) as opposed to 3 seconds during which measurement was made. Although not shown, z-axis length variation when operating at 30 , $40,50 \& 60 \mathrm{k} \mathrm{rpm}$ was measured and produced greater variation as speed was increased in line with results reported by Bissacco et al. [15] and Creighton et al. [16].

In an attempt to minimise apparent spindle length variation, changes were made to the acceleration and deceleration rates. Commercial considerations restrict complete disclosure of the changes however the nett effect was to significantly reduce error levels by $\sim 50 \%$. Fig. 9 shows slot depths following machining of graphite workpiece using the $6 \mathrm{~mm}$ diameter PCD end mill. Tool wear was negligible and therefore the deviation in programmed slot depth (nominally $50 \mu \mathrm{m}$ ) reflects the variation in $\mathrm{z}$-axis length due to thermal growth.

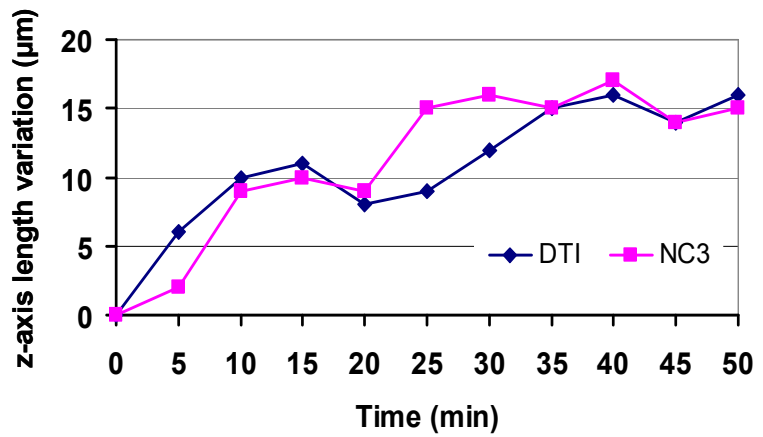

Fig. 8 Z-axis growth measured using DTI \& $\mathrm{NC} 3$ at $60,000 \mathrm{rpm}$

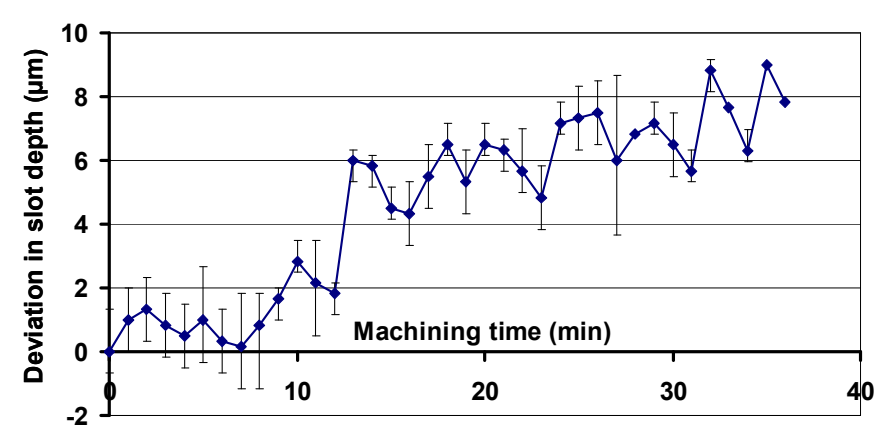

Fig. 9 Graphite slot depth measured using OMP 40 following modification of spindle accelerationdeceleration rate

\section{Conclusions}

The last decade has seen a rapid expansion in the production of micro components manufactured from conventional workpiece materials as opposed to silicon. Machining processes such as micro EDM and particularly micro end milling offer the potential to produce complex 3D components, the latter without restrictions on workpiece electrical properties but subject to the adverse effects of tool 
wear, cutting forces etc. Machine thermal growth and the resulting positional errors potentially have a more significant impact on workpiece quality and accuracy when machining at the microscale level, and the need to utilise spindles operating at $\sim 60000-160000 \mathrm{rpm}$ further exacerbates the problem, particularly with motor driven units incorporating conventional bearing systems. Analysis of a commercial micro/mesoscale high speed machining centre operating at up to $60,000 \mathrm{rpm}$ identified significant $\mathrm{z}$-axis spindle variation of up to $\sim 16 \mu \mathrm{m}$ following a standard warm-up cycle, despite employing an active spindle cooling system and coordinate compensation algorithms. Improved accuracy $(\sim 50 \%)$ was obtained through manipulation of spindle acceleration and deceleration rates with consequent effects on the rate of thermal loading and cooling.

\section{Acknowledgements}

The authors would like to thank Universiti Teknologi MARA, Malaysia for scholarship funding together with Adrian Barnacle from Mitsubishi Carbide UK for product and technical support. Additional thanks go to the University of Birmingham for access to machine tool and analysis equipment.

\section{References}

[1] M. Rahman, H.S. Lim, K.S. Neo, A. Senthil Kumar, Y.S. Wong and X.P. Li: J. Mater. Process. Technol. Vol. 185(1-3) (2007), p. 2.

[2] X. Liu, R.E. DeVor, S.G. Kapoor and K.F. Ehman: Trans ASME, J. Manuf. Sci. Eng. Vol. 126 (2004), p. 666.

[3] D. Dornfeld, S. Min and Y. Takeuchi: CIRP Ann., Manuf. Technol. Vol. 55/2 (2006), p. 745.

[4] J. Chae, S.S. Park and T. Freiheit: Int. J. Mach. Tools Manuf. Vol. 46 (2006), p. 313.

[5] G.M. Robinson, M.J. Jackson, and M.D. Whitfield: J. Mater. Sci. Vol. 42 (2007), p. 2002.

[6] S. Gowri, P.R. Ranjith Kumar, R. Vijayarajand and A.S.S. Balan: Int. J. Mater. Struct. Integrity. Vol. 1(1/2/3) (2007), p. 161.

[7] X. Liu, R.E. Devor and S.G. Kapoor: Trans ASME, J. Manuf. Sci. Eng. Vol. 129(3) (2007), p. 453.

[8] P. Li, J.A.J. Oosterling and A.M. Hoogstrate, in: Proceedings of the 2nd International Conference on Micromanufacturing, Greenville, USA (2007), p. 219.

[9] A. Aramcharoen and P.T. Mativenga: Precis. Eng. Vol. 33(4) (2009), p. 402.

[10] A. Aramcharoen, P.T. Mativenga, S. Yang, K.E. Cooke and D.G. Teer: Int. J. Mach. Tools Manuf. Vol. 48(14) (2008), p. 1578.

[11] Personal communication with A. Turner, Rainford Precision, (2009)

[12] R. Ramesh, M.A. Mannan and A.N. Poo: Int. J. Mach. Tools Manuf. Vol. 40(9) (2000), p. 1257.

[13] H.J. Pahk and S.W. Lee: Int. J. Adv. Manuf. Technol. Vol. 20(7) (2002), p. 487.

[14] M. Weck, P. McKeown, R. Bonse and U. Herbst: CIRP Ann., Manuf. Technol. Vol. 44/2 (2002), p. 589.

[15] G. Bissacco, H.N. Hansen and L. De Chiffre, in: Proc. of 4th EUSPEN International Conference - Glasgow, Scotland (2004).

[16] E. Creighton, A. Honegger, A. Tulsian and D. Mukhopadhyay: Int. J. Mach. Tools Manuf. Vol. 50(4) (2010), p. 386. 